doi: http://dx.doi.org/10.5892/ruvrv.2010.81.0718

ARTIGO / ARTICLE

\title{
ESTUDO DA PERCEPÇÃO DOS USUÁRIOS QUANTO AOS SERVIÇOS PRESTADOS NO ATENDIMENTO AO PÚBLICO DE UMA COOPERATIVA DE CRÉDITO DA CIDADE DE POMPÉU/MG
}

\begin{abstract}
Adriano Teles Fonseca ${ }^{1}$
Washington Moreira Cavalcanti ${ }^{2}$

Sérgio Ricardo Magalhães ${ }^{3}$

RESUMO

Este estudo pretendeu mostrar, através do método de pesquisa de campo, as percepções dos usuários de uma cooperativa de crédito, identificada COMÉRCIOCRED (nome fictício), quanto ao atendimento prestado ao público. As cooperativas de crédito são instituições financeiras constituídas sob a forma de sociedade cooperativa, tendo por objeto a prestação de serviços financeiros aos associados, como concessão de crédito, captação de depósitos a vista e a prazo, cheques, prestação de serviços de cobrança, de custódia, de recebimentos e pagamentos por conta de terceiros sob convênio com instituições financeiras públicas e privadas e de correspondente no país, além de outras operações específicas e atribuições estabelecidas na legislação em vigor. Após final do estudo, foi possível concluir que as cooperativas de crédito mantem estruturas muito parecidas com as estrutura de bancos comerciais de varejo, porém com o diferencial da forma de cooperativa, principalmente pela ênfase em linhas de crédito com juros baixos, o que tem levado este setor a crescer substancialmente. No caso da COMÉRCIOCRED, verificou-se um alto percentual de satisfação de seus associados, usuários e clientes em relação ao atendimento, serviços e crédito.
\end{abstract}

Palavras chave:Pesquisa de mercado, satisfação do cliente, cooperativa de crédito.

\begin{abstract}
This study aims to show, through the method of field research, the perceptions of users of a credit union, identified COMÉRCIOCRED (fictitious name), regarding the care provided to the public. Credit unions are financial institutions established in the form of a cooperative society having for its object the provision of financial services to members, such as lending, deposit-taking spot and forward, checks, service charge, custody, of receipts and payments on behalf of third parties under contract with public and private financial institutions and correspondent in the country, and other specific operations and tasks laid down in legislation. After the end of the study, it was concluded that credit unions maintain structures very similar to the structure of commercial banks in retailing, but with the differential form of the cooperative, especially the emphasis on lines of credit with low interest rates, which has led this sector to grow substantially. In the case of COMÉRCIOCRED, there was a high rate of satisfaction among their members, users and customers about the care, services and credit.
\end{abstract}

Keywords: Market research, Customer satisfaction, Cooperative credit.

\footnotetext{
1 e 2 Acadêmicos do curso de Administração da Universidade Vale do Rio Verde

${ }^{3}$ Professor do curso de Administração da Universidade Vale do Rio Verde
} 


\section{INTRODUÇÃO}

As cooperativas de crédito nasceram na Alemanha em 1848, assumiram características próprias desde que aportaram por aqui em 1902. Elas se transformaram em um segmento importante do Sistema Financeiro Nacional, tendo sofrido alterações de acordo com o desenvolvimento político e econômico da sociedade, destacando-se as regras baixadas pelo governo Vargas na década de 30 , e pelos governos militares na década de 60 , até chegarmos ao modelo atual, traçado pela Resolução $\mathrm{n}^{\circ}$ 3.442, de 2007, do Conselho Monetário Nacional, que consolida um novo cenário para o sistema de cooperativas de crédito que teve início em 2003, com a criação das cooperativas de livre admissão.

Sociedades cooperativas são sociedades de pessoas, com forma e natureza jurídica próprias, constituídas para prestar serviços aos associados, cujo regime jurídico, atualmente, é instituído pela Lei $n^{\circ} 5.764$, de 16 de dezembro de 1971.

Cooperativas de crédito são instituições financeiras constituídas sob a forma de sociedade cooperativa, tendo por objeto a prestação de serviços financeiros aos associados, como concessão de crédito, captação de depósitos a vista e a prazo, cheques, prestação de serviços de cobrança, de custódia, de recebimentos e pagamentos por conta de terceiros sob convênio com instituições financeiras públicas e privadas e de correspondente no país.

O crescimento e consolidação das cooperativas de crédito dependem de uma rápida evolução, tanto na estruturação de produtos mais adequados às necessidades desse segmento quanto na revisão dos sistemas que sustentam as operações e o modelo de gestão de cooperativas. A pesquisa é a chave para a compreensão da realidade, instrumento técnico que permite: o conhecimento do potencial do mercado, o direcionamento ou avaliação da propaganda, a eficiência do marketing, a elaboração de estratégias de persuasão.

Este artigo retrata a pesquisa que coletou informações precisas quanto à satisfação dos associados no atendimento, espaço físico e serviços oferecidos, procurando identificar os pontos positivos e negativos e, com isto, buscar a cada dia oferecer aos associados os melhores serviços e manter-se neste mercado tão competitivo quanto o mercado bancário e financeiro.

\subsection{Identificação da organização}

Sentindo a necessidade de se organizar em busca de uma redução das despesas bancárias, um grupo de comerciantes locais se reuniu para constituir um Posto de Atendimento ao Cooperado (PAC) que aqui terá o nome fictício de COMÉRCIOCRED. Tal PAC é filial de uma cooperativa da região que foi constituída em novembro de 2007 com o objetivo de apoiar e fortalecer o micro e pequeno empreendedor da cidade de Pompéu-MG e região. O PAC COMÉRCIOCRED foi inaugurado em 03/03/2008 com 60 (sessenta) associados, tendo alcançado já no primeiro ano de atividades um total de 198 (cento e noventa e oito) associados. O número de associados está sempre em crescimento devido aos resultados positivos que a instituição registra desde sua inauguração. A COMÉRCIOCRED é também conveniada com o Banco Cooperativo do Brasil S.A. - BANCOOB, para operacionalização das atividades da centralização financeira e serviços de compensação de documentos.

A cooperativa possui atualmente 767 associados, sendo a sede com 530 associados e o PAC COMÉRCIOCRED com 237 associados. Para se tornar associado o interessado preenche uma ficha de inscrição que é aprovada ou não pelos conselheiros e, se aprovado, o associado só efetiva sua participação após integralização de quota capital mínima conforme reza em seu estatuto. A cooperativa em sua totalidade possui uma equipe de 15 funcionários sendo: 2 gerentes, 2 tesoureiros, 3 caixas, 1 porteiro, 2 serviçais, 1 contador, 1 atendente e 3 estagiários. Destes funcionários, 7 trabalham nas instalações da COMÉRCIOCRED.

Os colaboradores recebem treinamentos mensais oferecidos pela central e mantém reuniões internas quinzenalmente ou semanalmente dependendo da necessidade. Uma equipe uniforme que busca prestar os melhores 
serviços aos associados e às pessoas que procuram a agência para usar qualquer outro serviço oferecido. dos mais prósperos municípios de Minas, com aproximadamente 30.000 habitantes. Pompéu tem sua economia baseada na pecuária de corte e leite,

\subsection{Estrutura organizacional}

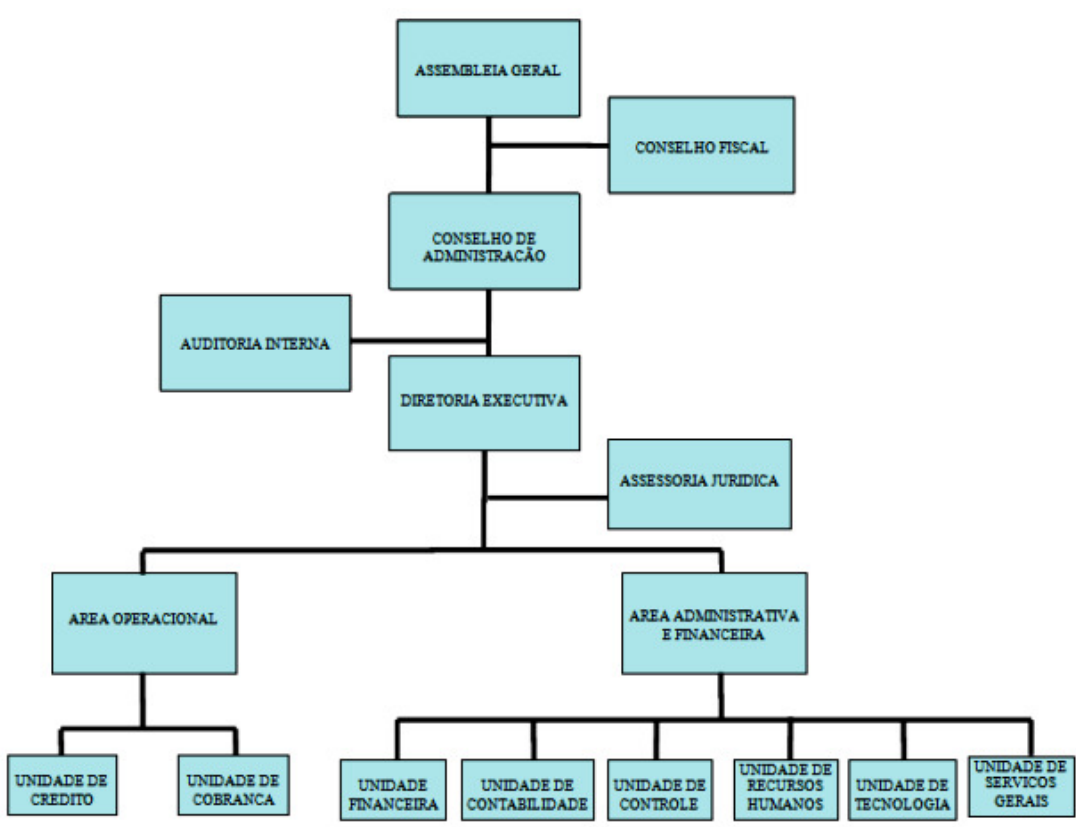

a maior bacia leiteira de Minas e o segundo lugar no Brasil, indústria moveleira, extração e beneficiamento de pedra ardósia e usina de produção de álcool combustível.

Recentemente, tornouse referência brasileira no cultivo de Agaricus Blazei - um cogumelo medicinal muito consumido no Japão, o que permite um promissor mercado exportador.

O Município está situado na região do alto São Francisco, fazendo divisa com os municípios de Abaeté, Martinho

Figura 1: Estrutura organizacional - COMÉRCIOCRED Fonte: COMÉRCIOCRED/2009.

Campos, Pitangui, Papagaios, Curvelo, Felixlândia e Morada

O órgão supremo da cooperativa é a Assembléia Geral, cabendo a esta tomar toda e qualquer decisão de interesse da entidade. Suas deliberações vinculam a todos, ainda que ausentes ou discordantes. Os negócios e atividades da cooperativa são fiscalizados assídua e minuciosamente por um Conselho Fiscal, constituído de 3 (três) membros efetivos e 3 (três) suplentes, todos cooperantes, eleitos anualmente pela Assembléia Geral, sendo permitida a reeleição de apenas 1/3 (um terço) dos seus componentes.

\subsection{Localização}

A cidade de Pompéu recebeu este nome como homenagem ao seu primeiro habitante, Antônio Pompeu Taques. A história do município remonta há mais de duzentos anos, mas somente em 1840 dá-se a fundação do arraial por Joaquim Cordeiro Valadares.

Há 181 km de Belo Horizonte, Pompéu é um

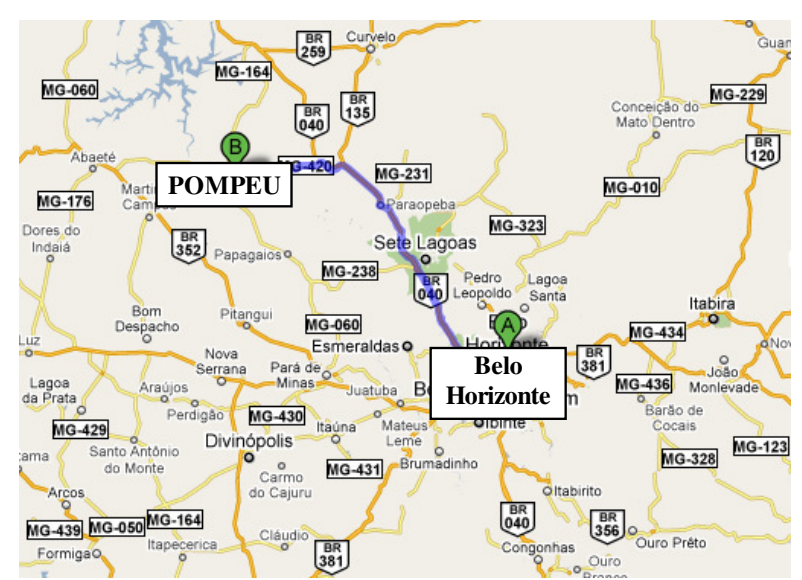

Nova de Minas.

Figura 2: Localização da Cidade de Pompéu/MG Fonte: Google / Maps.

\section{DEFINIÇÃO DE SERVIÇOS}

Os serviços são definidos na literatura 
econômica convencional como "bens intangíveis", conforme descrito por Gianesi (1994). A prestação de serviços às empresas compreende o setor terciário da economia envolve, bem como aos consumidores finais. Os serviços podem envolver o transporte, distribuição e venda de mercadorias do produtor para um consumidor que pode acontecer no comércio atacadista ou varejista, ou podem envolver a prestação de um serviço, como o antiparasitas ou entretenimento. Os produtos podem ser transformados no processo de prestação de um serviço, como acontece no restaurante ou em equipamentos da indústria de reparação. No entanto, o foco é sobre as pessoas interagindo com as pessoas e servindo ao consumidor, mais do que a transformação de bens físicos.

Em razão da intangibilidade inerente aos serviços, muitos gestores encontram dificuldades em identificar seus produtos. Fitzsimmons e Fitzsimmons (2002), definem pacote de serviços como um conjunto de mercadorias e serviços que são fornecidos em um ambiente. $\mathrm{O}$ autor divide este conjunto em quatro características, o quadro 1 exemplifica melhor estas características.

\begin{tabular}{|l|l}
\hline $\begin{array}{l}\text { Instalação de } \\
\text { apoio }\end{array}$ & $\begin{array}{l}\text { Instalações e equipamentos } \\
\text { utilizados no serviço. }\end{array}$ \\
\hline Bens facilitadores & $\begin{array}{l}\text { Itens físicos fornecidos ao } \\
\text { cliente. }\end{array}$ \\
\hline $\begin{array}{l}\text { Serviços } \\
\text { explicitos }\end{array}$ & $\begin{array}{l}\text { Principal razão da prestação } \\
\text { do serviço - benefícios } \\
\text { sensoriais. }\end{array}$ \\
\hline $\begin{array}{l}\text { Serviços } \\
\text { implícitos }\end{array}$ & $\begin{array}{l}\text { Benefícios psicológicos que o } \\
\text { cliente pode obter com a } \\
\text { prestação do serviço. }\end{array}$ \\
\hline
\end{tabular}

QUADRO 1: Características do pacote de serviço

Fonte: Adaptação Fitzsimmons e Fitzsimmons (2002)

Como o serviço é toda e qualquer atividade de inter-relacionamento entre um fornecedor e um consumidor e os resultados de todas as atividades do fornecedor para atender as necessidades do consumidor variam de acordo com a atividade, podemos relacionar as principais características dos serviços: Intangibilidade; Inseparabilidade; Variabilidade e Perecibilidade.

Estas características permitem que o papel das atividades de serviços na economia contemporânea seja, além do atendimento ao consumo final das sociedades, ser o facilitador destas transações econômicas, proporcionando os insumos essenciais ao setor manufatureiro, permitindo efeitos "para a frente e para trás" na cadeia produtiva, contribuindo com a expansão de pólos de desenvolvimento.

\subsection{Serviços bancários}

A seleção de serviços bancários tem como objetivo a fundamentação da escolha dos produtos e serviços financeiros a utilizar, a qual decorre da análise comparada das ofertas apresentadas pelas entidades financeiras consultadas.

Para compreender as características das instituições financeiras e não financeiras, é necessário, num primeiro momento, caracterizar a estrutura do sistema financeiro brasileiro. "O sistema financeiro nacional pode ser definido como o conjunto de instituições e órgãos que regulam, fiscalizam e executam as operações relativas à circulação da moeda e do crédito". (FERREIRA, 2003).

Os serviços bancários são regidos por normas definidas pelo Banco Central que regulamenta todo o sistema financeiro brasileiro.

Integram o sistema financeiro brasileiro: o Conselho Monetário Nacional, o Banco Central do Brasil, a Comissão de Valores Mobiliários, o Banco do Brasil, o Banco Nacional de Desenvolvimento Econômico e Social e outras instituições financeiras públicas e privadas, que são as operadoras do sistema financeiro. Dessa forma, o sistema financeiro é composto por instituições financeiras bancárias e não bancárias, das quais fazem parte os bancos comerciais e as cooperativas de crédito.

\section{COOPERATIVAS DE CRÉDITO}

As cooperativas de crédito são organizações que prestam serviços financeiros aos associados, razão pela qual são instituições importantes para o desenvolvimento de muitos países. Na Alemanha, essas cooperativas possuem cerca de 15 milhões de associados, que correspondem a cerca de $20 \%$ de todo o movimento financeiro e bancário desse país.

Segundo dados do Banco Central do Brasil, as cooperativas de crédito registraram expressiva expansão na última década. De 1993 a 2004, enquanto o número de instituições financeiras do País caiu quase à metade, ao diminuir de 1.065 
para 646, as cooperativas de crédito aumentaram de 877 para 1.436. A participação das cooperativas de crédito na área bancária do Sistema Financeiro Nacional ainda é pequena, mas o seu crescimento é significativo tanto no que diz respeito às operações de crédito quanto ao patrimônio líquido. Em 1995, as cooperativas de crédito detinham uma fatia de apenas $0,44 \%$ das operações de crédito, participação que avançou para 2,3\% em 2005.

As cooperativas são uma sociedade de pessoas com forma e natureza jurídica própria, de caráter civil, não sujeita a falência, constituída para prestar serviços de caráter financeiro-bancário aos associados e à comunidade onde atuam. A atuação das cooperativas está fortemente associada ao Estatuto Social, mediante aprovação pelos seus associados em Assembléia Geral, seguindo os princípios básicos do cooperativismo e a legislação que regulamenta a sua existência.

As cooperativas de crédito, pela resolução 2.193/95, obtiveram autorização para constituir bancos cooperativos controlados por elas próprias. fundado em 1995, em Porto Alegre - RS, integrando o Sistema de Crédito Cooperativo (Sicredi) e o Banco Cooperativo do Brasil S.A (Bancoob), fundado em 1997, com sede em Brasília - DF, integrando os Sistemas de Cooperativas de Crédito Regionais do Brasil (Sicoob).

Apesar do potencial de crescimento do segmento no Brasil e da importância que vem adquirindo, é grande o desconhecimento sobre cooperativismo de crédito no Brasil, tanto por parte do público em geral, quanto mesmo por parte de conceituados autores.

\section{PESQUISA DE CAMPO}

O tipo de pesquisa utilizado é a exploratória e descritiva que realiza uma interrogação direta das pessoas, cuja opinião que quer conhecer e tem como vantagem o conhecimento direto da realidade, a economia, rapidez e a quantificação dos dados. Um modelo que permite trabalhar a pesquisa de opinião procurando saber pontos de vista com o objetivo de subsidiar a tomada de decisões e coletar dados quantitativos em um campo específico que neste caso é a cooperativa.

Podendo assim definí-la como pesquisa de levantamento que permite fazer uma investigação direta com pessoas para conhecer-lhes algo e obter informações de um grupo significativo de pessoas e após análise dos dados projeta-se para o universo pesquisado.

\subsection{Amostragem e coleta de dados}

A amostragem probabilística foi constituída de 30 questionários resultando em uma amostra representativa da população. Os dados da população foram retirados da pesquisa de opinião aplicada na cidade de Pompéu e, através da coleta de dados, foi possível perceber que entre homens e mulheres entrevistados a maioria compreende os homens na faixa etária entre 36 a 45 anos e acima de 45, comerciários casados e com escolaridade secundária, cuja renda é de 2 a 4 salários.

Hoje, há no Brasil, dois bancos cooperativos: o Banco Cooperativo Sicredi S.A (Bansicredi), 
Para a elaboração dos instrumentos de coleta de dados procedeu-se inicialmente a uma pesquisa bibliográfica, por meio de consultas a fontes diretas ou indiretamente relacionadas ao tema a ser tratado.

De posse de todas as informações consideradas relevantes e necessárias passou-se então para a fase de formulação de hipóteses e de construção das questões que poderiam ser abordadas junto aos entrevistados que são atendidos por serviços prestados por uma cooperativa de crédito, objeto deste estudo.

\subsection{Análise dos dados}

A hipótese que norteou a proposta de abordagem teórica aqui apresentada é que a natureza específica das atividades de serviço reside no fato de serem essencialmente realização de trabalho - independentemente das características formais do processo produtivo ou do produto resultante deste processo.

Explícita ou implicitamente os clássicos e os autores contemporâneos sempre trataram os serviços como realização de trabalho. Entretanto, há diferenças básicas, de ordem conceitual e metodológica, da hipótese de que serviço é realização de trabalho, derivam-se três premissas:

1. Serviço é trabalho na sua acepção ampla e fundamental, podendo ser realizado não só através dos recursos humanos (trabalho humano) como também através das máquinas e equipamentos (trabalho mecânico).

2. Serviço é trabalho em processo, ou seja, serviço é trabalho na concepção dinâmica do termo, trabalho em ação.

3. Todo serviço é realização de trabalho, mas nem toda realização de trabalho é serviço, ou seja, não existe uma relação biunívoca entre serviço e trabalho.

A classificação dos serviços torna-se bastante ampla, sendo possível identificá-los ao longo das etapas da realização do trabalho nos processos econômicos em geral, como no setor financeiro e bancário.

Para este estudo, com foco na prestação de serviços de uma cooperativa de crédito, foram a aplicados questionários aos clientes e usuários dos serviços da cooperativa, os dados foram tabulados e analisados. Através das análises dos resultados obtidos pela aplicação do questionário, foram colhidas opiniões dos clientes e usuários alvos desta pesquisa, com o intuito de avaliar a percepção sobre os serviços tradicionais e monitorar a qualidade de atendimento na cooperativa de crédito do município de Pompéu.

Para processar, analisar e interpretar os resultados obtidos com a pesquisa quantitativa utilizou-se o método de análise descritivo, baseado em valores absolutos e percentuais de análise de dados, quando necessário.

\subsubsection{Característica e perfil da amostra}

A caracterização da amostra foi efetuada nas questões de 01 a 09 e teve por objetivo definir o perfil dos clientes da cooperativa de crédito, bem como seus dados sócio-econômicos, assim como permitir outras análises.

O primeiro dado de relevância é o que demonstra que o perfil de sexo dos usuários se apresenta em sua grande maioria de pessoas do sexo masculino, da seguinte forma: $73,3 \%$ de pessoas do sexo masculino e $26,7 \%$ do sexo feminino.

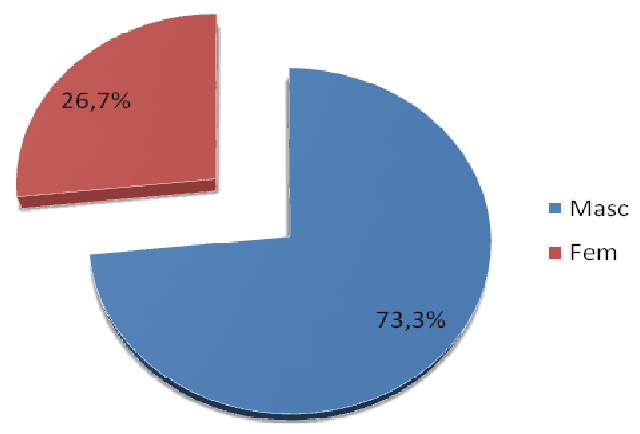

Gráfico 1 - Sexo dos clientes

Em termos de faixa etária, os clientes com maior incidência foram os usuários com idade entre 36 e 45 anos com 36,7\% da amostragem, o restante dos pesquisados apresentaram os seguintes dados.

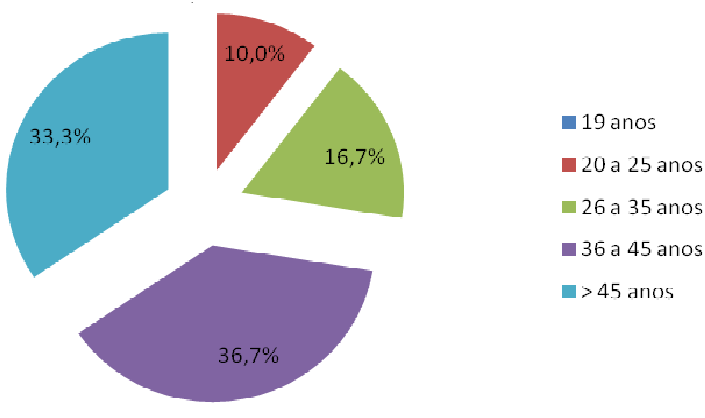

Revista da Universidade Vale do Rio Verde - ISSN: 1517-0276

Edição Especial do Curso de Administração a Distância, campus Betim - vol. 8, n.1/2010 
Gráfico 2 - Faixa etária dos clientes

A escolaridade apresentada na pesquisa se concentrou principalmente nos clientes de formação secundária com $66,7 \%$ do levantamento.

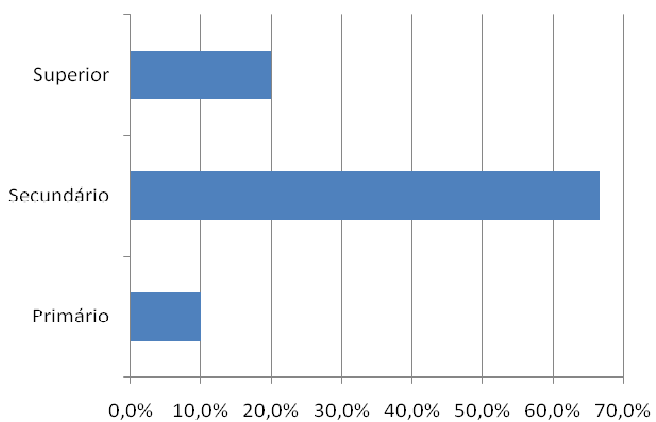

Gráfico 3 - Escolaridade dos clientes

Em termos de atividade profissional, os dados referentes à ocupação dos clientes, apresentaram os comerciários com maior índice, dos quais $50 \%$ dos entrevistados estão nesta atividade.

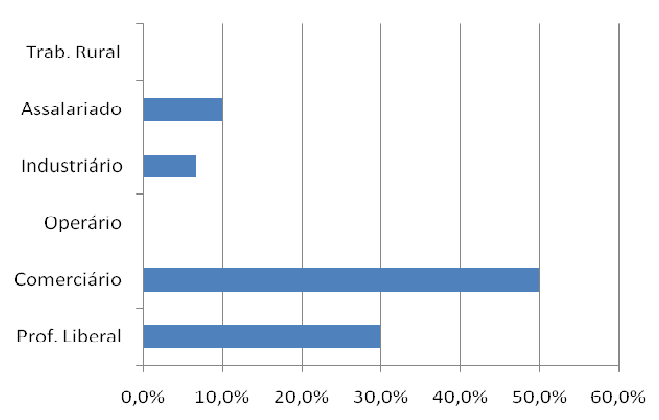

Gráfico 4 - Áreas de ocupação dos entrevistados

A renda familiar das pessoas entrevistadas apresentou uma concentração na faixa de dois a quatro salários mínimos, com um percentual de 40\% dos questionários respondidos.

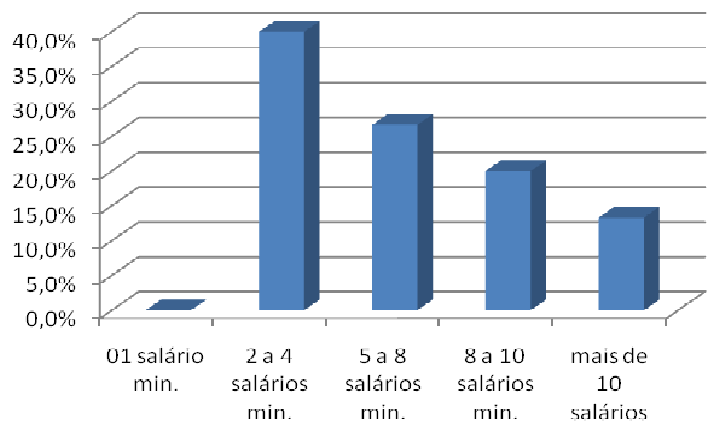

Gráfico 5 - Renda familiar dos pesquisados

Fator de extrema importância para o resultado da pesquisa é o número de idas à agência e de utilizações dos serviços da cooperativa, com um percentual de $60 \%$ responderam que utilizaram os serviços mais de dez vezes no último mês anterior à aplicação do questionário.

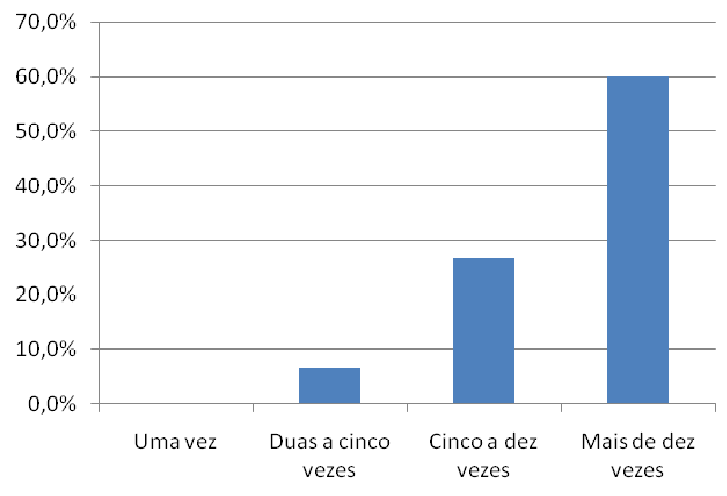

Gráfico 6 - Utilização dos serviços da cooperativa no ultimo mês

Tal fato demonstra a qualidade dos serviços prestados são determinantes na sustentação e ampliação da base de clientes correntistas associados e dos clientes que utilizam os serviços de "boca de caixa".

\subsection{Análise do nível de satisfação e do grau de importância dada aos diversos atributos identificados no atendimento}

A análise do nível de satisfação e do grau de importância dos atributos foi baseada na avaliação de sete blocos em que foram agrupados temas importantes para o cliente. O nível de satisfação por bloco de questões identificadas neste estudo são definidos por uma graduação que retrata a satisfação em uma escala descrita em: Excelente, Bom, Médio, Fraco e Ruim.

É importante ressaltar que alguns dos entrevistados fizeram a opção de não responder algumas das questões propostas, ou por não terem informação sobre o serviço, ou por não fazer parte do escopo de serviços utilizados pelo cliente. Nestes casos não ocorreram à marcação de dados percentuais, o que pode resultar em um somatório inferior a $100 \%$ dos dados listados em cada tabela. 


\begin{tabular}{lrrrrc}
\hline & Excelente & Bom & Médio & Fraco & Ruim \\
\hline Atendimento prestado pelo Caixa & & & & & - \\
\hline 10. Atendimento ao público/cordialidade & $93,3 \%$ & $6,7 \%$ & - & - & - \\
\hline 11. Apresentação pessoal do caixa & $83,3 \%$ & $16,7 \%$ & - & - & - \\
\hline 12. Agilidade no atendimento & $66,7 \%$ & $26,7 \%$ & $6,7 \%$ & - & - \\
\hline 13. Conhecimento das atividades da função & $56,7 \%$ & $43,3 \%$ & - & - & - \\
\hline 14. O caixa se mostrou "PROATIVO" & $56,7 \%$ & $40,0 \%$ & - & - & - \\
\hline
\end{tabular}

Tabela 1 - Grupo de questões: Atendimento prestado pelo Caixa

Os blocos de questões se descortinam a seguir:

- Atendimento prestado pelo Caixa: Neste bloco pode-se observar como é a percepção dos clientes frente à qualidade do atendimento prestado pelo caixa durante a atividade e serviços ofertados ao usuário. No quesito "Atendimento ao público/cordialidade" $93,3 \%$ responderam que o atendimento foi excelente, contra apenas $6,7 \%$ creditaram como bom o atendimento.

Dois fatores chamam a atenção nesta análise, "Conhecimento das atividades da função" e "o caixa se mostrou PROATIVO", descreveram uma redução da satisfação dos usuários cujos índices se posicionaram em $56,7 \%$ em excelente e $43,3 \%$ e $40 \%$ como bom para cada uma das opções respectivamente. colaboradores. "Os itens de maior satisfação apresentados são os "Profissionais de segurança (atendimento)" e "Mobiliário de atendimento (compreende mesas, cadeiras, poltronas, balcões, entre outros)", em seguida pode-se observar que os "Profissionais de limpeza/manutenção" também colaboraram com um percentual elevado na visão dos clientes.

Fatores a serem observados por seu menor índice de satisfação foram o "Atendimento telefônico" e os serviços prestados pelos "Atendentes de balcão". Estes dados demonstram uma situação de alerta por parte da administração da cooperativa.

\begin{tabular}{lccccc}
\hline & Excelente & Bom & Médio & Fraco & Ruim \\
\hline Serviço de atendimento (Geral) & & & & & \\
\hline 15. Atendimento telefônico quando utilizado & $56,7 \%$ & $26,7 \%$ & $3,3 \%$ & - & - \\
\hline 16. Atendentes de balcão (informações) & $56,7 \%$ & $33,3 \%$ & $3,3 \%$ & - & - \\
\hline 17. Profissionais de segurança (atendimento) & $70,0 \%$ & $20,0 \%$ & - & - & - \\
\hline 18. Profissionais de limpeza / manutenção & $66,7 \%$ & $23,3 \%$ & - & - & - \\
\hline $\begin{array}{l}\text { 19. Mobiliário de atendimento (compreende: } \\
\text { mesas, cadeiras, poltronas, balcões, etc.) }\end{array}$ & & & & & - \\
\hline 20. Comunicação e informações & $70,0 \%$ & $26,7 \%$ & - & - & - \\
\hline
\end{tabular}

Tabela 2 - Grupo de questões: Serviço de atendimento (Geral)

- Serviço de atendimento (Geral): A Tabela 2, descreve a percepção dos clientes para os serviços prestados pelos atendentes e demais funcionários e
- Estrutura física / localização: Verificou-se que nos dados referentes à estrutura física da agência da cooperativa, 
foi possível descrever a percepção dos clientes para os itens de acessibilidade, espaço, transportes e segurança. $\mathrm{O}$ item
Porém o "Tempo de respostas às solicitações e questionamentos" se mostrou em um patamar muito abaixo ao anterior, com apenas 30\%

\begin{tabular}{llllll}
\hline & Excelente & Bom & Médio & Fraco & Ruim \\
\hline Estrutura física / localização & & & & & \\
\hline 21. Localização da agência & $73,3 \%$ & $20,0 \%$ & $3,3 \%$ & - & - \\
\hline 22. Transporte / estacionamento & $36,7 \%$ & $50,0 \%$ & $6,7 \%$ & - & - \\
\hline 23. Espaço físico da agência & $46,7 \%$ & $46,7 \%$ & $3,3 \%$ & - & - \\
\hline 24. Acesso pessoal às dependências da agência & $50,0 \%$ & $43,3 \%$ & $3,3 \%$ & - & - \\
\hline 25. Segurança e limpeza & $60,0 \%$ & $33,3 \%$ & $3,3 \%$ & - & - \\
\hline
\end{tabular}

Tabela 3 - Grupo de questões: Estrutura física / localização

de maior pontuação, ou seja, apontado como excelente, foi a "Localização da Agência", seguido da "Segurança e Limpeza" das instalações.

O fator preocupante, demonstrado pela Tabela 3, foi o "Espaço físico da Agência" com índice de $46,7 \%$ dos entrevistados que apontaram como apenas bom as instalações da cooperativa.

- Operação dos serviços - Burocracia: Estes serviços, descritos na Tabela 4, se apresentam como os mais críticos do setor bancário. Alguns fatores alteraram os índices de satisfação, principalmente por falhas na informação ou desconhecimento dos usuários.

A disponibilidade de instruções e informações sobre os serviços se apresentou como satisfatória, com um percentual de 53,3\% como excelente. identificado como excelente.

É válido ressaltar que os "serviços de malote" apresentaram um índice de 33,3\% como bom, porém, nem todos os clientes entrevistados utilizam este tipo de serviço.

- Serviços de crédito / Juros e Taxas bancárias: Na Tabela 5, verifica-se que a satisfação quanto à condição dos serviços de crédito, incidência de juros e das taxas bancárias, os índices de satisfação foram muito abaixo dos identificados nos grupos anteriores.

O item "Ao fazer uso dos serviços de crédito e financiamento, como foi o atendimento" obteve somente $30 \%$ de percepção dos usuários como excelente. No atributo de conhecimento entre as diferenças das taxas de um banco e da cooperativa, $43,3 \%$ dos entrevistados classificaram como boas ou médias as informações dadas sobre este assunto.

\begin{tabular}{|c|c|c|c|c|c|}
\hline & Excelente & Bom & Médio & Fraco & Ruim \\
\hline \multicolumn{6}{|l|}{ Operação dos serviços - Burocracia } \\
\hline \multicolumn{6}{|l|}{ 26. Disponibilidade de } \\
\hline instruções dos serviços prestados & $53,3 \%$ & $26,7 \%$ & $3,3 \%$ & - & - \\
\hline 27. Serviços de malote & $20,0 \%$ & $33,3 \%$ & - & - & - \\
\hline 28. Freqüência na utilização do malote & $23,3 \%$ & $20,0 \%$ & - & - & - \\
\hline \multicolumn{6}{|l|}{ 29. Tempo de respostas às } \\
\hline solicitações e questionamentos & $30,0 \%$ & $36,7 \%$ & $13,3 \%$ & - & - \\
\hline 30. Conveniência de serviços prestados & $36,7 \%$ & $43,3 \%$ & - & - & - \\
\hline
\end{tabular}

Tabela 4 - Grupo de questões: Operação dos serviços - Burocracia 


\begin{tabular}{|c|c|c|c|c|c|}
\hline & Excelente & Bom & Médio & Fraco & Ruim \\
\hline \multicolumn{6}{|l|}{ Serviços de crédito / Juros e Taxas bancárias } \\
\hline \multicolumn{6}{|l|}{ 31. Ao fazer uso dos serviços de crédito } \\
\hline e financiamento, como foi o atendimento & $30,0 \%$ & $23,3 \%$ & $10,0 \%$ & - & - \\
\hline \multicolumn{6}{|l|}{ 32. Qual a sua satisfação em relação } \\
\hline aos serviços de crédito e financiamento & $26,7 \%$ & $26,7 \%$ & $6,7 \%$ & $3,3 \%$ & - \\
\hline \multicolumn{6}{|l|}{ 33, Qual a disponibilidade de linhas } \\
\hline de crédito e financiamento & $23,3 \%$ & $20,0 \%$ & $13,3 \%$ & $6,7 \%$ & - \\
\hline \multicolumn{6}{|l|}{ 34. Você tem conhecimento da diferença em } \\
\hline \multicolumn{6}{|l|}{ relação aos juros e taxas da } \\
\hline \multicolumn{6}{|l|}{ Cooperativa de Crédito e as } \\
\hline praticadas pelo mercado financeiro & $16,7 \%$ & $30,0 \%$ & $13,3 \%$ & - & - \\
\hline \multicolumn{6}{|l|}{ 35. Ao fazer uso dos serviços de } \\
\hline \multicolumn{6}{|l|}{ Internet Banking e qual a } \\
\hline percepção do serviço & $23,3 \%$ & $26,7 \%$ & - & - & - \\
\hline
\end{tabular}

Tabela 5 - Grupo de questões: Serviços de crédito / Juros e Taxas bancárias

Outro fator importante demonstrado na pesquisa foi o baixo índice de respostas dadas aos serviços prestados via internet. Apenas $23,3 \%$ dos entrevistados apresentaram sua opinião como excelente. Estes dados demonstram uma menor penetração dos serviços por internet junto ao seu público alvo.

A adoção de uma nova sistemática de comunicação e divulgação destes serviços proporcionaria um maior grau de esclarecimento sobre a real situação dos serviços via internet da cooperativa. Além disso, possibilita mais agilidade no seu atendimento apresentando, assim, um resultado mais fidedigno aos seus associados.

- Impressão geral da Cooperativa de Crédito: As cooperativas do sistema adotam procedimentos bastante conservadores, utilizando-se de todas as variáveis importantes e necessárias para $\mathrm{o}$ relacionamento com o cliente, pois precisam, além de fornecer serviços aos seus associados, criar as condições que justifiquem a sua existência; ainda, precisam apresentar índices de liquidez $\mathrm{e}$ rentabilidade para dar sustentação ao empreendimento e segurança aos associados aplicadores.

O item "Impressão geral da Cooperativa de Crédito" nos permite ter uma visão geral da percepção que o cliente e usuário tem para este tipo de instituição. $O$ quesito confiabilidade apresenta um índice de 93,3\% de satisfação entre excelente e bom.

Já os fatores "Ética e Transparência" e "Relacionamento e Parceria", demonstram que os clientes não somente confiam na cooperativa como também a tem como uma parceira em suas atividades empresariais, ou não. Por sinal, os índices foram respectivamente de $53,3 \%$ de excelente e $40 \%$ de bom na percepção dos usuários.

\begin{tabular}{lccccc}
\hline & Excelente & Bom & Médio & Fraco & Ruim \\
\hline Impressão geral da Cooperativa de Crédito & & & & & \\
\hline 36. Confiabilidade & $53,3 \%$ & $40,0 \%$ & - & - & - \\
\hline 37. Modernidade & $46,7 \%$ & $43,3 \%$ & $3,3 \%$ & - & - \\
\hline 38. Segurança & $40,0 \%$ & $33,3 \%$ & $20,0 \%$ & - & - \\
\hline 39. Ética e transparência & $53,3 \%$ & $40,0 \%$ & - & - & - \\
\hline 40. Relacionamento e parceria & $53,3 \%$ & $40,0 \%$ & - & - & - \\
\hline
\end{tabular}

Tabela 6 - Grupo de questões: Impressão geral da Cooperativa de Crédito 
FONSECA, A. T.; CAVALCANTI, W. M; MAGALHÃES, S. R.

\begin{tabular}{lccccc}
\hline & Excelente & Bom & Médio & Fraco & Ruim \\
\hline Reclamações & & & & & \\
\hline 41. Agilidade de solução & $46,7 \%$ & $26,7 \%$ & $10,0 \%$ & - & - \\
\hline 42. Receptividade a reclamações & $50,0 \%$ & $33,3 \%$ & - & - & - \\
\hline 43. Boa vontade e prontidão & $70,0 \%$ & $16,7 \%$ & - & - & - \\
\hline
\end{tabular}

Tabela 7 - Grupo de questões: Reclamações

- Reclamações: Finalmente, o último grupo de questões sobre os serviços ofertados pela cooperativa. A fidelização do cliente passa por uma maior agilidade na solução de problemas e na ação a respostas solicitadas pelos usuários.

Um fator de destaque foi que, ao serem questionados sobre a "Boa vontade e prontidão" ao ser efetuada uma reclamação, $70 \%$ afirmaram ser excelente o atendimento a resposta solicitada. Também foi destaque o fato de que $83,3 \%$ dos entrevistados afirmarem que a "Receptividade a reclamação" está em um nível entre excelente e bom.

A "Agilidade de solução" apresentou um viés declinante não muito acentuado, porém, 46,7\% afirmaram ser excelente a solução a uma reclamação e $36,7 \%$ descreveram que o tempo de resposta se apresentou médio ou bom.

A principal finalidade de uma cooperativa de crédito é liberar recursos a seus associados, assim, podemos perceber que a política adotada pela cooperativa na administração da sua carteira de clientes foi eficaz. Além disso, o perfil dos associados é, basicamente, formado por pessoas do sexo masculino, com idade de 36 a 45 anos, com atuação no comércio, com renda de dois a quatro salários mínimos e, invariavelmente, essa composição da carteira de clientes contribui para a manutenção dos atuais patamares de adimplência. Deve-se, também, considerar o fato de se tratar de uma cooperativa, o que contribui para que os associados tenham mais cuidado com o seu patrimônio e consequentemente, no relacionamento com a própria cooperativa.

Ao final das análises, as avaliações foram muito semelhantes em todos os atributos. Verificou-se uma tendência dos entrevistados em assinalar "Excelente" e "Bom" na maioria dos itens, fazendo com que as médias ficassem sempre elevadas, fato que valida a pesquisa efetuada e abre caminho para uma possível coleta de dados aberta e qualitativa.

\section{CONSIDERAÇÕES FINAIS}

A corrida pela redução de custos com melhoria da qualidade, disponibilidade e facilidade de acesso aos produtos e serviços oferecidos aos clientes, leva as empresas a participarem de cooperativas.

As fusões e incorporações, vem crescendo com o objetivo de ganho de escala nos serviços comuns e aumento da capacidade de investimentos tecnológicos e negociais, com isso a COMÉRCIOCRED demonstra sua preocupação junto aos seus associados, em gerar retorno financeiro, prestar bons serviços proporcionando melhoras na qualidade de vida de seus cooperados.

Um dos principais pontos observados no processo de pesquisa gira em torno da possibilidade de obtenção de linhas de crédito mais acessíveis as suas necessidades, especialmente no que se refere à taxa de juros, tarifas, prazos e garantias.

Alcançar este objetivo é possível por serem, as cooperativas de crédito, entidades sem fins lucrativos e trabalharem com estruturas operacionais simplificadas e com capital próprio.

A COMÉRCIOCRED vem atender as necessidades das empresas associadas, oferecendo serviços bancários, linhas de crédito a custos menores, com agilidade e boa qualidade sendo esta uma das soluções encontradas para que as empresas possam se manter no mercado reduzindo custos e utilizando todos os serviços que necessitam.

A pesquisa também mostrou que a cooperativa existe para beneficiar e atender os seus associados em primeiro lugar. 


\section{REFERÊNCIAS}

AZEVEDO, Sérgio César de. Guia valor econômico de marketing para pequenas e médias empresas. São Paulo: Globo, 2002.

FERREIRA, R. J. Sistema Financeiro

Nacional. Publicado em mar. 2003. Disponível em:

$<$ http://www.editoraferreira.com.br/publique/m edia/01SFN.pdf $>$. Acesso em: 05 de Junho 2009.

FITZSIMMNOS, J. A.; FITZSIMMONS, M. J. Administração de Serviço: operações, estratégia e tecnologia de informação. Porto Alegre: Bookman, 2002.

GIANESI, I. G. N.; CORRÊA, H. L. Administração estratégica de serviços: operações para satisfação do cliente. São Paulo: Atlas, 1994.

HOFFMAN, K. Douglas. Princípios de Marketing de Serviços: conceitos, estratégias e casos. São Paulo: Pioneira Thomson Learning, 2003.

MEINEN, E.; DOMINGUES, N.J.; DOMINGUES, S.A.J. Aspectos jurídicos do cooperativismo. Porto Alegre: Saga Luzzatto, 2001.

PINHEIRO, Marcos Antônio Henriques. Cooperativa de crédito. - História de Crédito. 5 ed. Brasília: Independente, 2007. 